\title{
Towards Establishing Climatic Thresholds for Slope Instability: Use of a Physically-based Combined Soil Hydrology-slope Stability Model
}

\author{
S. M. Brooks ${ }^{1}$, M. J. Crozier ${ }^{2}$, T. W. Glade ${ }^{3}$, \\ and M. G. ANDERSON ${ }^{4}$
}

\begin{abstract}
Shallow landslides are often linked to high magnitude rainstorms. Research has attempted to establish threshold rainfall totals that trigger shallow landslides, based mainly on field evidence. Complications arise because not all regolith has the same hydrological behaviour, and research frequently fails to take this into account. This paper uses a combination of field and modelling approaches to explore the triggering rainfall thresholds for shallow failures in deforested hill country of New Zealand. It emphasises the role of variations in regolith hydrology, focussing on unsaturated and saturated zone responses. By using a modelling approach, detailed variations in pore pressure (positive and negative) responses are investigated, developing ideas initially derived from field evidence. This paper defines and develops earlier research that establishes values for maximum and minimum probability thresholds for shallow landslides, and provides a more generalised model that can be applied more widely. Hydrological mechanisms for shallow landslides are investigated in greater detail than previously possible using a Combined Hydrology And Stability Model $\left(\mathrm{CHASM}^{\mathrm{TM}}\right)$.
\end{abstract}

Key words: Shallow landslides, soil hydrology, triggering rainfall thresholds, physically-based modelling.

\section{Introduction}

Shallow regolith failures affect much of New Zealand hill country and are responsible for considerably accelerated soil erosion in recent times. While there is evidence for periods of accelerated soil erosion in the Holocene related to warming trends and associated enhanced cyclonic activity (GRANT, 1983), it has been shown that a major factor responsible for the recent increase in the occurrence of shallow regolith failures is removal of indigenous forest and conversion to pasture by European settlers (PAge and Trustrum, 1997; WiLkinson, 2000).

\footnotetext{
${ }^{1}$ School of Geography, Birkbeck College, Gresse Street, London WIP 2LL, UK. E-mail: s.brooks@bbk.ac.uk

${ }^{2}$ Victoria University of Wellington, Wellington, New Zealand.

${ }^{3}$ Geographisches Institut, University of Bonn, Meckenheimer Allee, Bonn, Germany.

${ }^{4}$ School of Geographical Sciences, University of Bristol, University Road, Bristol BS8 1SS.
} 
Currently, the hill slopes of much of New Zealand are undergoing episodic regolith stripping (CROZIER and PRESTON, 1999; BROOKS et al., 2002), involving an upslope progression of regolith removal by landslides and exposure of the underlying parent material. The main agent responsible for this process is rainfall (generally cyclonic rainfall associated with tropical storms), although seismic activity can also remove large amounts of material under both shallow and deep-seated failure (CROzIER, 1997). Climatic triggers to shallow slope failure can be isolated from seismic factors since the latter produce clusters of both shallow and deep-seated failures, while the former tend to result only in shallow failures (CROZIER, 1997). Shallow planar slope failures, occurring within the regolith above the bedrock substrate provide the focus for this paper.

There is now a large body of field evidence from the hill country of New Zealand regarding the distribution of shallow failures caused by high-magnitude rainstorms in recent years, in a variety of regoliths forming on different bedrock substrates (Crozier and Pillans, 1991; Crozier et al., 1980; Preston, 1996; Glade, 1997, 1998, 2000; Glade and Crozier, 1996; Glade et al., 2000). Detailed accounts of the storm properties that produce shallow landslides are also available. A major impetus for these field observations has been the possible identification of climatic thresholds for slope failure, and a closer understanding of the landslide-climate link, especially for slopes that have undergone removal of vegetation. As CROZIER (1997) states:

"Most modelling efforts to date have been spent on the development of regional empirical threshold models. These appear to have been successful for the place and period from which they were derived but most of them require further testing and refinement."

(CROZIER, 1997: p. 344)

In general, many empirical thresholds are available in the literature. The simplest involve linking the properties of individual storms, such as intensity or duration, to the occurrence of slope failure (e.g., CAINE, 1980; PAGE et al., 1994), although there is now a range of thresholds based on antecedent moisture levels as well (KIM et al., 1992; CROZIER, 1997). The results of KIM et al. (1992) are particularly interesting, as they suggest that the significant climatic parameters vary between regions. Areas of central Korea, for example, have failures that are controlled mainly by the 3-day cumulative rainfall total while in southern Korea, daily rainfall is more important. Implicit in this is that a complex interplay operates between rainfall and regolith/ substrate material hydrology, similar to that modelled by FreEzE (1980), both of which vary regionally. Hence, as CROzIER (1997) suggests, results from empirical threshold models are not spatially and temporally transferable.

Rigorous definition of climatic thresholds for slope instability can be misleading in so far as they imply that failure will inevitably occur once the threshold is exceeded. However, it is often the case that these thresholds are exceeded without failure occurring (CROZIER, 1997). A more applicable approach possibly involves recognition of minimum and maximum probability thresholds (GLADE and CROZIER, 
1996). The minimum probability threshold defines the point below which failure will not occur, but above which it may occur under certain circumstances. The maximum probability threshold defines the condition above which there is $100 \%$ probability of instability. GLADE (1997) has defined these thresholds for three regions of North Island, New Zealand, using different types of model: the daily rainfall model (GLADE, 1997, 1998, 2000), the antecedent rainfall model (GLADE, 1998, 2000) and the antecedent soil water status model (GLADE et al., 2000).

These regions are shown in Figure 1. The daily rainfall model suggests that the minimum probability threshold is around $20 \mathrm{~mm}$ per day for the three regions of Wellington, Hawkes Bay and Wairarapa, while the maximum probability threshold varies from $120 \mathrm{~mm}$ per day at Wairarapa, through $140 \mathrm{~mm}$ per day at Wellington to $300 \mathrm{~mm}$ per day at Hawke's Bay. The larger events have approximate recurrence intervals of 3.7, 10.5 and 32 years respectively, although the smaller threshold might be exceeded about once every 9 days in Hawke's Bay and every 91 days in Wairarapa/Wellington. These different rainfall amounts between the three regions suggest that there may be significant variations in regolith-bedrock substrate hydrology that affect the occurrence of shallow slope failures. In particular, the differences may be expected to be greatest between Hawke's Bay and Wellington/ Wairarapa. The latter two regions have similar thresholds, implying either similar regolith-substrate hydrology or the presence of some other factors that dictate similar susceptibility to a given rainfall input. Investigation of rainfall/stability relationships will thus be focused on only two of the regions, Wellington and Hawke's Bay.

Identification of such climatic thresholds provides no causal mechanisms for failure, although it is suggested in this paper that the hydrological behaviour of the regolith/parent material is fundamental. To address this issue, CROZIER (1997) has attempted to apply a simple model to provide a preliminary process-based explanation of the link between climate and slope failure (Fig. 2). The model is based on the interplay between rainstorm properties (event water) and antecedent water, in relation to soil transmissivity at the ground surface. Two cases are identified, the first involving a situation in which rainfall intensity exceeds soil transmissivity, and water is lost to overland flow. In this case both storm total and rainfall intensity are poor properties from which to derive landslide-triggering thresholds. In the second case, rainfall intensity is lower than soil transmissivity at the ground surface and all water enters the soil. It is argued that in this case, storm totals and rainfall intensities do provide good measures for deriving landslidetriggering thresholds. Such general models are potentially of greater applicability to a range of soils having a range of transmissivities.

In most humid regions, where soil cover exceeds about $1 \mathrm{~m}$ and has an uncompacted open porous structure, saturated hydraulic conductivities are of the order $30-40 \mathrm{~mm} / \mathrm{h}$, but with great variability. With soil of very fine texture and heavy compaction, often due to anthropogenic activity, these rates are much lower. In most 


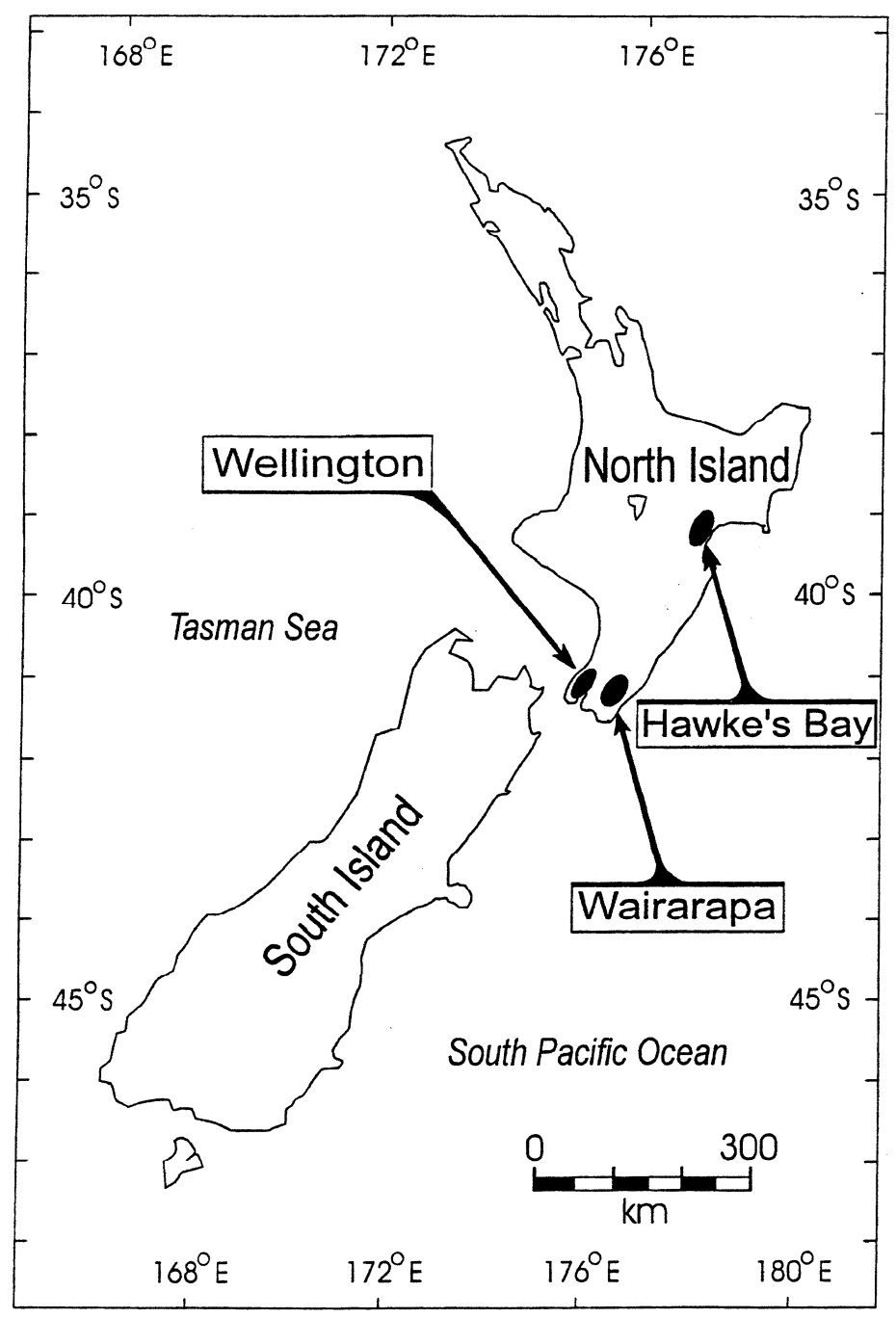

Figure 1

Location of the study sites at Hawkes Bay and Wellington New Zealand.

circumstances, however, the former condition applies and it is only under the most extreme events that rainfall intensities exceed soil transmissivities for sustained periods. It therefore follows that case one, identified by Crozier, is comparatively uncommon.

In much of New Zealand hill country, regolith depths are of the order 1-2 metres, especially on the steeper slopes undergoing shallow failure. Vertically-percolating water encounters the bedrock or substrate relatively quickly after the start of rain where regolith has a saturated hydraulic conductivity in excess of $30-40 \mathrm{~mm} / \mathrm{h}$. Of 


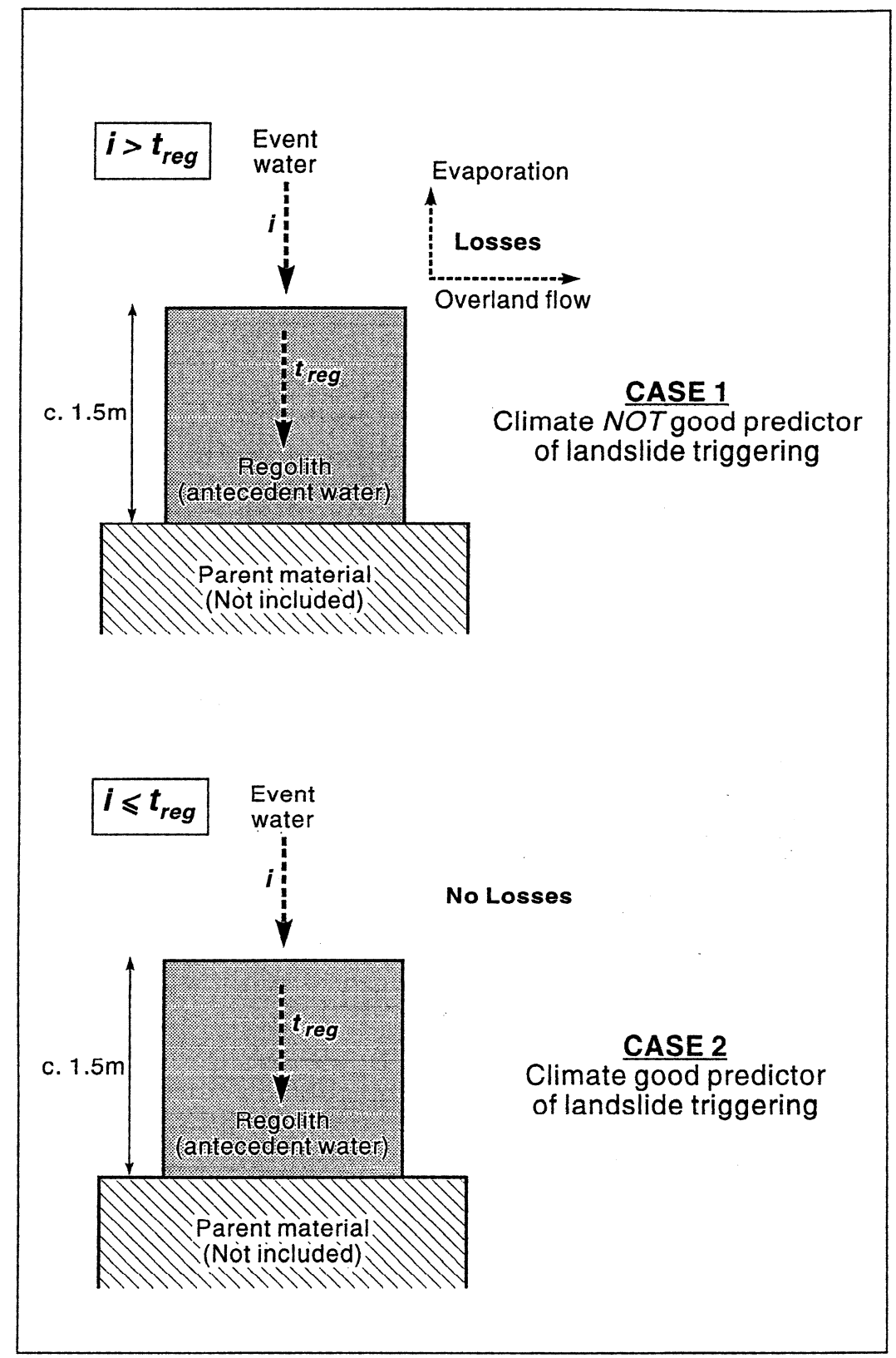

Figure 2

The Crozier (1997) model to assess the links between climate and landslides (see text).

significance in this case is the hydraulic conductivity of the bedrock relative to rainfall intensity. Excess water will not be lost but may facilitate the generation of positive pore water pressures within the lower part of the regolith. If the regolith has 
a higher hydraulic conductivity than the underlying bedrock or substrate, and the rainfall intensity falls between the saturated hydraulic conductivity of the regolith and the bedrock, then the situation is similar to that of case 1 (described above), with the significant boundary being the regolith-bedrock junction rather than the ground surface. However, unlike for case 1 where the ground surface acts as the boundary, this situation does not involve the loss of event water to overland flow or evaporation, and triggering thresholds might well be determined by rainfall totals and/or intensities.

Case 2 with all rainfall entering the soil, is most commonly found at the onset of rainfall. Hence it is the unsaturated behaviour of the regolith that is significant. This determines both the response rate and the minimum suctions (negative pore water pressures) that develop. Again, assuming that the regolith-substrate boundary is the significant boundary, then the most important relationship is the transmissivity of the regolith relative to the bedrock. Under conditions where both regolith and substrate transmissivity remain higher than rainfall intensity, and regolith transmissivity is lower than that of the substrate, unsaturated conditions determine slope stability criteria. Conversely, if regolith transmissivity is greater than that of the substrate, saturated conditions are readily attained at the regolith-substrate boundary and slope failure occurs via the development of positive pore water pressures.

To assess this in detail is problematic in the field, and requires a more detailed modelling approach in which dynamic unsaturated and saturated hydrology can be examined at depth in layered structures. The model used needs to have a sound process basis to be applicable to a range of regolith-substrate combinations and to be able to capture the effect of dynamic variations in rainfall intensity. It also needs to be capable of simulating the effect of lateral flow under saturated conditions which may develop at the regolith-substrate boundary. The model therefore needs to be formulated in at least 2 dimensions.

In this paper we apply a 2-D version of the dynamic, physically-based combined soil hydrology and slope stability model ( $\mathrm{CHASM}^{\mathrm{TM}}$ ) to investigate the hydrological mechanisms that produce shallow regolith failure and hence, elucidate in some detail the climate-landslide coupling. Contrasting scenarios are selected for analysis involving different substrate and regolith hydrological properties, the first from the Wellington region and the second from Hawke's 'Bay.

Although it is not the aim of this paper to predict the occurrence of slope failure, in order to use the model to elucidate the hydrological and climatological thresholds for slope instability, then it is necessary to ensure that the model is suitable for such a purpose. Predominantly this involves assembling evidence that the model has the correct process basis and is correctly discretised in space and time to perform robustly under the conditions being investigated. Hence some initial model validation was attempted. A detailed assessment of both saturated and unsaturated hydrological behaviour was then carried out to show how both are important in 
determining climatic thresholds for failure. Finally, the model was used to examine variations in bedrock-regolith hydrology resulting in differing climatological thresholds, and to show how these thresholds can be defined rigorously in physical terms, rather than simply stating a single rainfall intensity applicable to a given region.

\section{A Physically-based Model for Assessing Climate Thresholds for Slope Failure}

The Combined Hydrology And Slope Stability Model (CHASM ${ }^{\mathrm{TM}}$ ) is a generally applicable model for shallow and deep-seated slope failures that are governed by changing pore water pressures. This paper examines its suitability for exploring links between climate and regolith-substrate hydrology, in particular for the hill country of New Zealand. Unlike previous applications of slope stability models that make simplifying assumptions about the position of the water-table (CARSON and PETLEY 1970; CARson, 1975; Rouse and Farhan, 1975), the focus here is on dynamic hydrology, with unsaturated zone behaviour being represented in detail.

The model is capable of a high degree of spatial and temporal discretisation allowing the significance of hydrological discontinuities, such as occur at the regolithsubstrate boundary, to be represented in detail. In many regions of the World, such discontinuities have commonly been cited as the cause of shallow slope failures (CAMPBELL, 1975) as well as promoting positive pore water pressures and lateral through flow in the regolith. The capability to represent systems in a highlydiscretised manner also enables short-term (hourly or less) variations in rainfall intensity to be included in the analysis.

The CHASM $^{\mathrm{TM}}$ model has been described in other papers (ANDERSON et al., 1988; BROOKS et al., 1993a; 2002) and will not be described further in this paper. The most comprehensive outline of the early model developments can be found in ANDERSON et al. (1988) and the most recent developments in model capability are outlined by WiLKINSON (2000). The model has recently been applied to landslides occurring in the Hawke's Bay region (BROOKS et al., 2002), and preliminary evaluation of model applicability to landslides triggered by heavy rainfall in New Zealand can be found there. In this paper the model will be used more generally to advance understanding of climate-landslide links.

Two sites in New Zealand provide a suitable basis for model parameterisation, with a focus on those parameters important for both unsaturated and saturated hydrological behaviour of the regolith and substrate. The sites provide significant contrasts in regolith hydrology, and are from areas for which considerable effort has been expended in deriving empirical climatic thresholds for landslide initiation (Glade, 1997, 1998, 2000; Glade et al., 2000). The same sites also enable preliminary validation to be attempted, as a check for robust model performance under appropriate conditions for these climatically-triggered shallow slope failures. 


\section{Study Sites from the Hill Country of North Island, New Zealand}

Two study sites were selected for detailed analysis (Fig. 1). Both are located on the North Island of New Zealand, the first being on the southwest coast (Wellington) and the second being on the east coast (Hawke's Bay). Both regions have been the subjects of detailed field observations of contemporary slope failures occurring since deforestation. The general setting for slope failures in the Wellington region is described by CROzIER et al. (1992), while Hawke's Bay slope failures have received detailed attention from Preston (1996), Crozier and Preston (1999), and Brooks et al. (2002). A high-intensity rainfall event occurring on 19-20th December, 1976 in Wellington/Hutt Valley delivering over $300 \mathrm{~mm}$ of rainfall in 24 hours, and Cyclone Bola (which occurred in Hawke's Bay from 6-9th March, 1988 with a total rainfall of $724.75 \mathrm{~mm}$, and over $300 \mathrm{~mm}$ on 7th March alone) stand out from all recent events as they were both associated with widespread shallow translational failure. These two events were used in the validation.

In Wellington, failures were observed on both artificial cut slopes as well as on natural slopes. In the latter case the slips seemed to emanate from colluvial-filled bedrock depressions, similar to those described by RENEAU et al. (1989). CROZIER et al. (1992) describe the geotechnical properties of the regolith, modal slope angles and typical depths. During failure the regolith is stripped to the bedrock surface which in this region, is an indurated Mesozoic greywacke. However, CROzIER et al. (1992) point out that these colluvial-filled bedrock depressions can also be found on unconsolidated river gravels and on soft Tertiary marine sediments.

Modal slope angles for slopes experiencing regolith failure in the Wellington region are typically around $34^{\circ}$. The colluvium in bedrock depressions in which the slope failures take place averages around $2-3 \mathrm{~m}$ in depth, but in places reaches depths of $6 \mathrm{~m}$. It possesses an open porous structure, with overall porosity being around 56\%. Hence it is of comparatively low density (@1.3 g/cc), similar to most unconsolidated soils. Triaxial tests produced values for residual cohesion and angle of internal friction of $0.8 \mathrm{kPa}$ and $32^{\circ}$, respectively. The angle of friction of the underlying bedrock is similar to that reported for Grade IV weathered greywacke (CROzIER, 1989), with lower values for porosity (17-25\%), hence higher bulk densities $(2.02-2.54 \mathrm{~g} / \mathrm{cc})$. Grade IV weathered greywacke has been found to possess negligible cohesion and has a residual angle of internal friction of 35 degrees.

As well as the geotechnical properties, it is vital to consider the hydrological characteristics of the regolith and parent material. Measurements of saturated hydraulic conductivity in this regolith suggest values of around $50 \mathrm{~mm} / \mathrm{h}$. Given the higher density of the Grade IV weathered greywacke, saturated hydraulic conductivity is an order of magnitude lower, being about $2 \mathrm{~mm} / \mathrm{h}$. Soil moisture characteristic curves have been measured for the $\mathrm{A}, \mathrm{B}$ and $\mathrm{C}$ horizons of soils in the locality (McConchie, pers comm). Typical curves for surface regolith and underlying bedrock are plotted in Figure 3. 


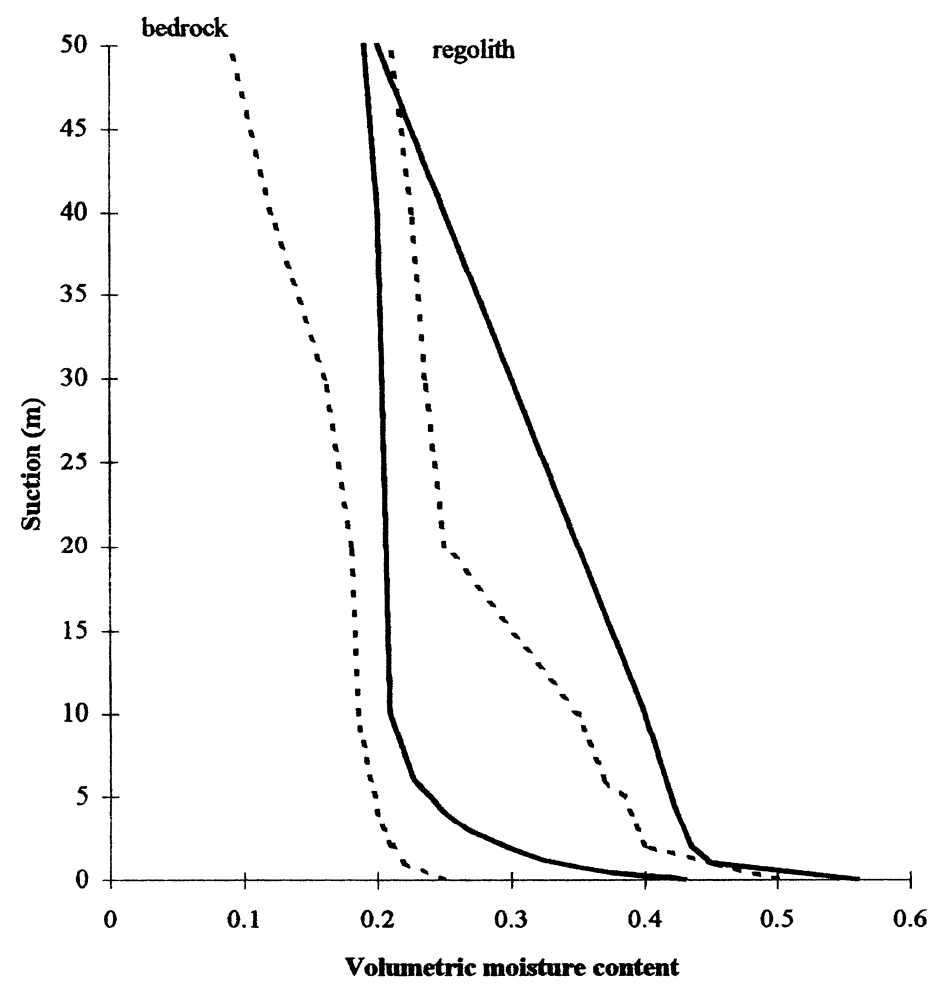

Figure 3

Soil moisture characteristic curves for the bedrock substrate and regolith for Wellington (dashed line) and Hawkes Bay (solid line) (note lower moisture contents at given suctions for the bedrock substrate compared with the regolith).

Within the Tutira area, near Hawke's Bay, the geology is somewhat different from that of Wellington. Here a combination of Tertiary and early Pleistocene marine sandstones and silty mudstones dominates, with interbedded limestone outcrops. The regolith is composed of a combination of weathering products from the silty and sandy parent material, along with Aeolian inputs of tephra and tephric loess (PAge and Trustrum, 1997; Preston, 1996). The area experienced widespread slope failure during Cyclone Bola, which is fully described by PAGE and TRUSTRUM (1997), and has recently been modelled by BROOKs et al. (2002).

Using a variety of sites around the Tutira catchment, PRESTON (1996) found regolith depths averaging $1 \mathrm{~m}$, but reaching $1.6 \mathrm{~m}$ in places. These depths are slightly shallower than for Wellington. The regolith is also more porous, having bulk densities 
in the region of $1.21 \mathrm{~g} / \mathrm{cc}$. The colluvial deposits downslope from the exposed failure surfaces are slightly denser (@1.27 g/cc), consistent with similar measurements for the Wellington colluvium. However, it is not the colluvium which is undergoing failure but the regolith further upslope. Bulk densities of the parent material are in the region $1.6 \mathrm{~g} / \mathrm{cc}$. PReston (1996) also carried out extensive direct shear box tests and found unexpectedly low values for residual angle of internal friction in the regolith, around $18^{\circ}$. However, this is consistent with the idea that angles of friction vary with normal load to become relatively high near the ground surface. At depths of $1.5 \mathrm{~m}$, direct shear measurements show that residual angles of internal friction may reach up to $30^{\circ}$ (Crozier and Preston, 1999). For simplified comparison of the hydrological behaviour in regolith from both Wellington and Hawke's Bay, it will be assumed that the angles of internal friction are similar in both regoliths. An appropriate value, justified by drained direct shear measurements is $30^{\circ}$.

Hydrological data are also available for the regolith and bedrock of the Hawke's Bay region. Measurements of saturated hydraulic conductivity of the regolith have been carried out by MERz (1987), who obtained mean values of $58 \mathrm{~mm} / \mathrm{h}$ for a variety of surfaces excluding recent slide scars. HENNRICH (2001), who calculated hydraulic conductivities by measuring rates of movement of the wetting front, found values from $41-145 \mathrm{~mm} / \mathrm{h}$ with a mean of $83 \mathrm{~mm} / \mathrm{h}$. CROZIER et al. (1980) in similar hill country in Wairarapa provided an average value of $150 \mathrm{~mm} / \mathrm{h}$ for soil supporting undisturbed pasture, appropriate for the failures being investigated in this paper. Measurements taken at the exposed shear surface representative of the saturated hydraulic conductivity of the bedrock substrate, are two orders of magnitude lower at $3.7 \mathrm{~mm} / \mathrm{h}$. Again, soil moisture characteristic curves were obtained by Jensen (pers. comm.) for soils in the region, and these are also plotted in Figure 3.

While it is argued that it is realistic to maintain similar values for the geotechnical properties of both regolith types (those of the bedrock, below the shear surface, are not relevant), there are two important distinctions in hydrological properties. Firstly, bedrock saturated hydraulic conductivity is lower than that of the regolith for both sites, but is somewhat lower in Wellington than Hawke's Bay. Secondly, there is a greater difference in the saturated hydraulic conductivity of the regolith, with the less dense material from Hawke's Bay having higher values than Wellington. Following from this is a greater difference between the regolith and bedrock saturated hydraulic conductivity for Hawke's Bay compared with Wellington. The differing densities of both types of regolith and of the bedrock in the two regions result in variations in the soil moisture retention curves. The combination of contrasting saturated hydraulic conductivities as well as soil moisture retention curves is expected to result in varying hydrological behaviour in both the saturated and unsaturated phases of water redistribution. This will be investigated further for its the significance to the derivation of appropriate climatic thresholds for slope failure in the two regions. 


\section{Model Validation Using Contemporary Slope failures}

Several key issues concerning applications of physically-based models have been identified recently, summarized by BEVEN $(1989,1997)$ and BRoOKS et al. (1999). It is frequently suggested that validation may be impossible (FAwCETT et al., 1992; DE Roo, 1996). However, it is necessary to ascertain that the model selected provides insight into the general behaviour of physical systems, is robust and suited to the problem being addressed. Process representation is central. If a model completely fails to predict slope instability, even when it is observed in the field, then the model almost inevitably has an incorrect process basis, an insufficiently-detailed discretisation routine or an inaccurate parameter set. Such would be the case were $\mathrm{CHASM}^{\mathrm{TM}}$ to be used to assess tectonically-triggered deep-seated landslides.

This paper uses a model that represents hydrological behaviour in detail. There are several shallow failures known to be triggered by rainstorms alone (CROZIER, 1997), and these form the basis for testing model performance. Successful prediction of shallow failure under the same conditions as measured in the field indicates that the model is appropriate. An alternative validation strategy (FAwCETT et al., 1992) involves measurement of internal variables (pore water pressures). For this paper, such an opportunity was not provided, although monitoring programmes are currently being established to meet this requirement.

For the different sites described above, for which appropriate parameterisation data are available, several recent shallow slope failures have been observed (GLADE and CROZIER, 1996) and associated hourly rainfall has been measured. CHASM ${ }^{\mathrm{TM}}$ simulations were carried out for the two sites using the two-dimensional version. The modelled factors of safety are shown in Figure 4. Under both storms failure is predicted by the model and is observed in the field. Significant differences are apparent between the two sites. The storm affecting the Wellington region is of higher intensity, shorter duration and lower total rainfall than that of the Hawke's Bay region. Despite higher rainfall intensities, the Wellington site takes longer to respond to rainfall, reaching a factor of safety of unity some 20 hours after the peak in intensity. In Hawke's Bay the lower peak rainfall intensity of $25 \mathrm{~mm} / \mathrm{h}$ produces failure after just 4 hours. The rainfall data for the entire Cyclone Bola show that such intensities are readily exceeded later in the storm. Consequently, the factor of safety remains below unity for some time.

These model results imply that there are different thresholds for slope failure in the two regions, as suggested from empirical evidence by GLADE $(1997,1998,2000)$, and that these are dictated by regolith and bedrock hydrology. The two storms are very different in intensity and duration, making it impossible to use these storms to directly compare the pore pressure response between the two regions, and thereby to ascertain general thresholds for landsliding. However, since Figure 4 shows that the model is capable of predicting actual occurrence of slope failure, it is be possible to use the model to investigate the hydrological mechanisms that generate low factors of 


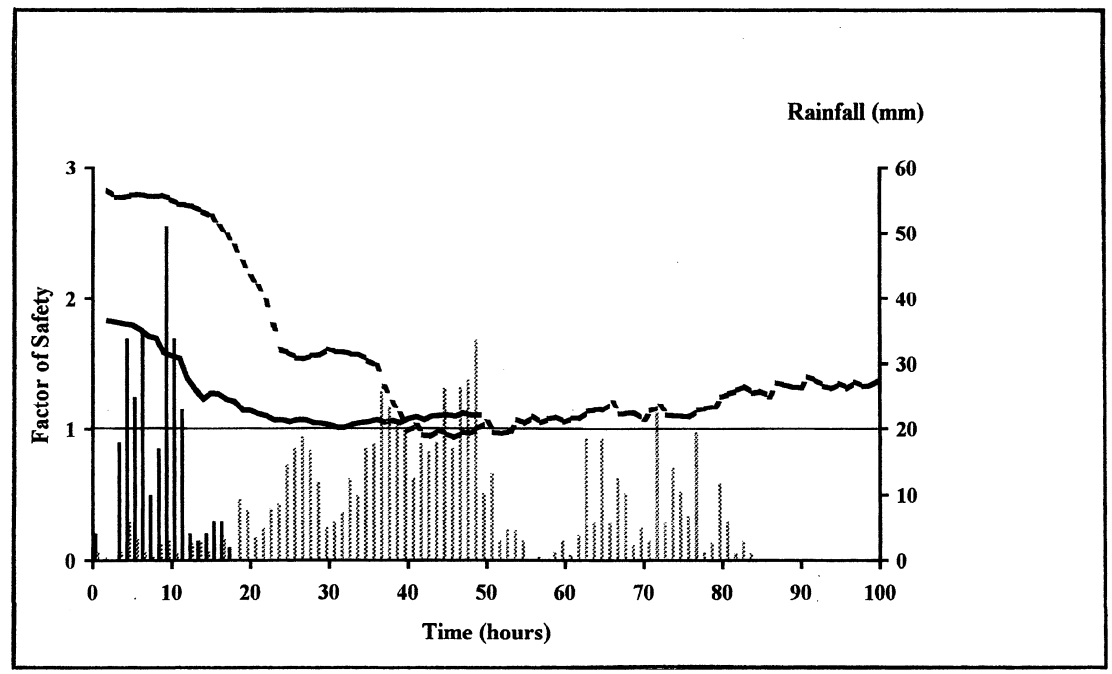

Figure 4

Changes in factor of safety under extreme events occurring at Hawkes Bay (dashed line) and Wellington (solid line) (rainfall = bars; factor of safety $=$ lines). (Note both regoliths are predicted to fail during these events, consistent with field observations).

safety under 'synthetic' storms of similar intensity. This analysis should allow more rigorous definitions to be provided for the climatic thresholds identified empirically by GLAde $(1997,1998,2000)$. Additionally it is the aim of this paper to provide a generalized conceptual model that builds on the ideas suggested by CROZIER (1997).

\section{Hydrological Mechanisms Underlying Shallow Slope Failure}

The most informative output from the combined hydrology and stability model is the variation in pore water pressure (positive and negative) over time for different depths in the regolith. To investigate contrasting hydrological responses in more detail, four simulations were carried out for each site involving steady rainfall intensities of $1 \mathrm{~mm} / \mathrm{h}, 10 \mathrm{~mm} / \mathrm{h}, 30 \mathrm{~mm} / \mathrm{h}$ and $50 \mathrm{~mm} / \mathrm{h}$, applied for 24 hours. These intensities span the range identified by GLADE (1997, 1998, 2000) as representing minimum and maximum probability thresholds for Wellington/ Wairarapa and Hawke's Bay, as well as taking the investigation to the higher intensities that may be sustained for shorter durations than 24 hours. Figures 5(a-h) plot pore water pressures for depths of $25 \mathrm{~cm}, 75 \mathrm{~cm}$ and $125 \mathrm{~cm}$ for the four intensities, for Hawke's Bay and Wellington. Figure 6 shows pore water pressure (positive and negative) variations for a depth of $125 \mathrm{~cm}$. This is simply to enable comparison at a depth where both negative and positive pore water pressures occur under the different storms. 

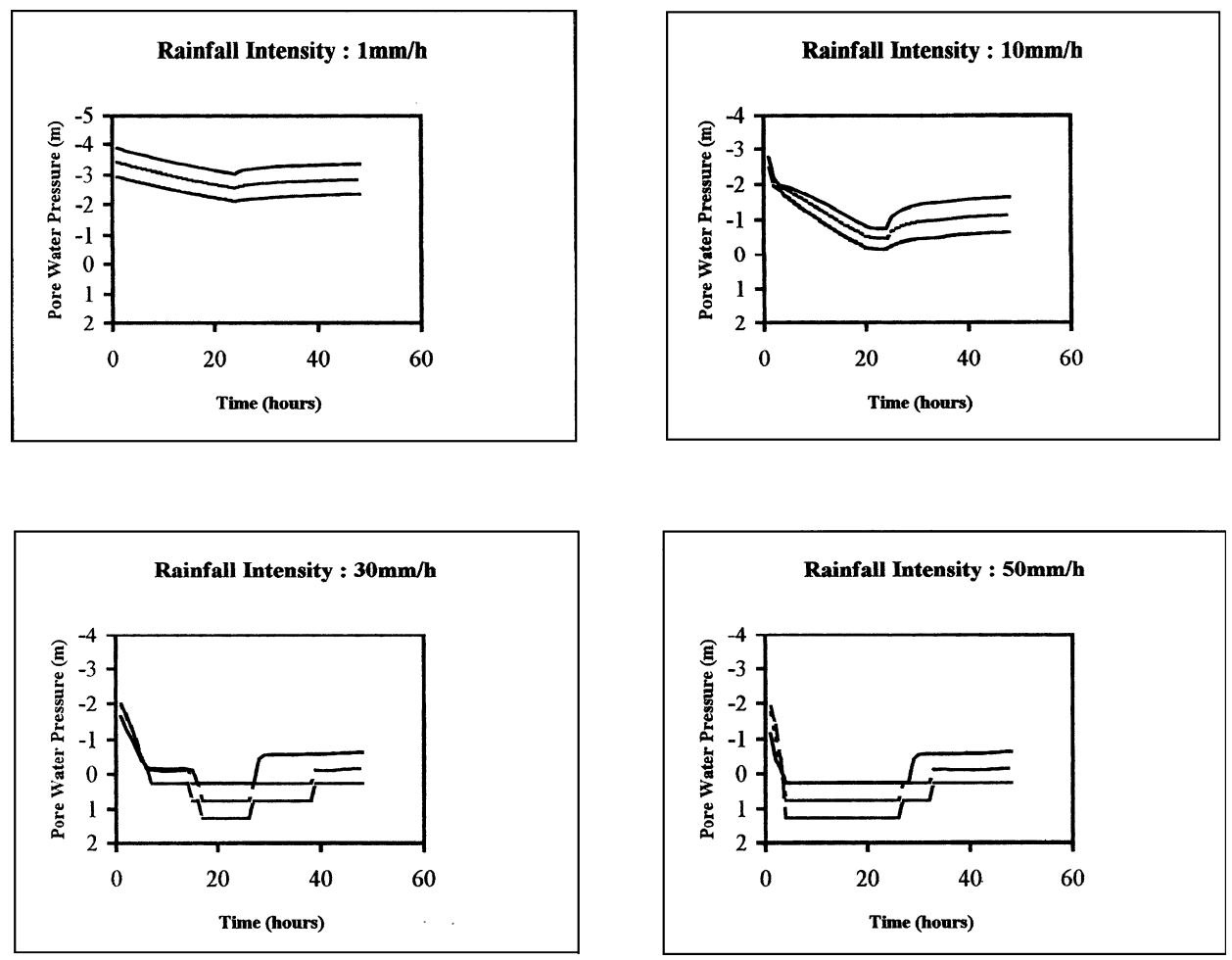

Figure 5

Pore water pressure variation at depth for different rainfall intensities and locations: (a-d) Hawkes Bay region.

Under $1 \mathrm{~mm} / \mathrm{h}$ rainfall intensity, both regoliths remain unsaturated with a progressive lag in response with depth. Minimum suctions (negative pore water pressures) attained are lower for Wellington than for Hawke's Bay regolith. $1 \mathrm{~mm} / \mathrm{h}$ is close to the minimum probability threshold for both regions $(20 \mathrm{~mm}$ in 24 hours $\approx 0.83 \mathrm{~mm} / \mathrm{h}$ ). When the rainfall intensity increases to $10 \mathrm{~mm} / \mathrm{h}$, there are several notable differences in response. Pore water pressures drop ultimately to lower values and do so at a faster rate. While the regolith at the Hawke's Bay site remains unsaturated throughout, the deepest part of the Wellington regolith becomes saturated after 18 hours. For an intensity of $30 \mathrm{~mm} / \mathrm{h}$ complete regolith saturation occurs for Wellington after 11 hours (all three depths showing positive pore water pressures), and for Hawke's Bay after 17 hours. Finally, for $50 \mathrm{~mm} / \mathrm{h}$ complete regolith saturation also occurs, but in both cases the response is faster.

It is clear that there are threshold rainfall intensities that control whether the regolith remains unsaturated, becomes saturated only at depth, or becomes saturated throughout the whole profile. Rainfall intensities of $1 \mathrm{~mm} / \mathrm{h}$ are insufficient for saturation at any depth, but $30 \mathrm{~mm} / \mathrm{h}$ produces complete saturation. Taking 
Wellington Region
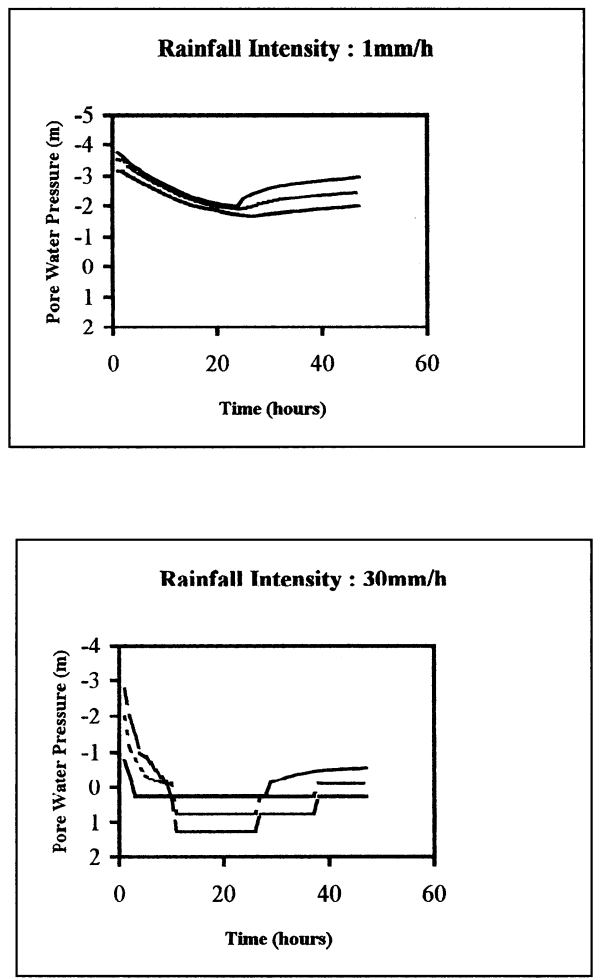
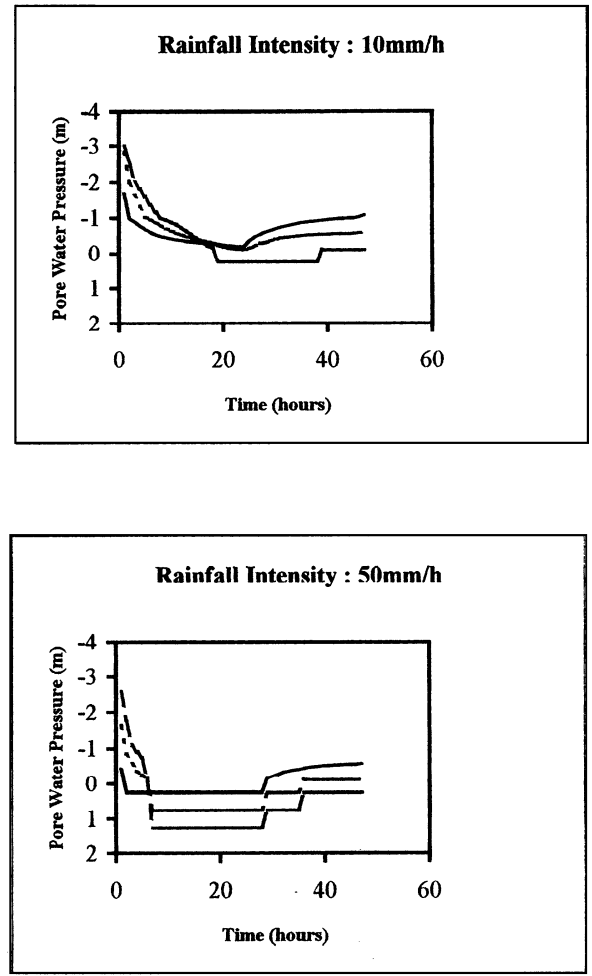

Figure 5 (e-h)

Wellington region

Hawke's Bay, the minimum and maximum probability thresholds as defined by $\operatorname{Glade}(1997,1998,2000)$ are approximately $1 \mathrm{~mm} / \mathrm{h}(0.83 \mathrm{~mm} / \mathrm{h})$ and $10 \mathrm{~mm} / \mathrm{h}$ $(12.5 \mathrm{~mm} / \mathrm{h})$ respectively. In Wellington, the minimum probability threshold is the same, but the maximum is $5.6 \mathrm{~mm} / \mathrm{h}$, somewhat lower. The significance of these thresholds is more readily seen from a plot of unsaturated hydraulic conductivity variation with suction (Fig. 7). Several methods exist for deriving this relationship from soil moisture retention curves and saturated hydraulic conductivity (MILLINGTON and Quirk, 1959; CAMPBEll, 1974; VAN GenuChten, 1980). In these examples, the method of Campbell was selected since the required parameters are readily available from measured data and the method is simple to apply for this initial analysis.

The minimum probability threshold in both Hawke's Bay and Wellington relates to a rainfall intensity for which saturation is impossible (shown as ' $x$ ' on the "horizontal axis" in Fig. 7). The rainfall rate remains lower than the saturated hydraulic conductivity of both the bedrock and the regolith. All rain will enter the regolith and will percolate through to the underlying bedrock without generation of 


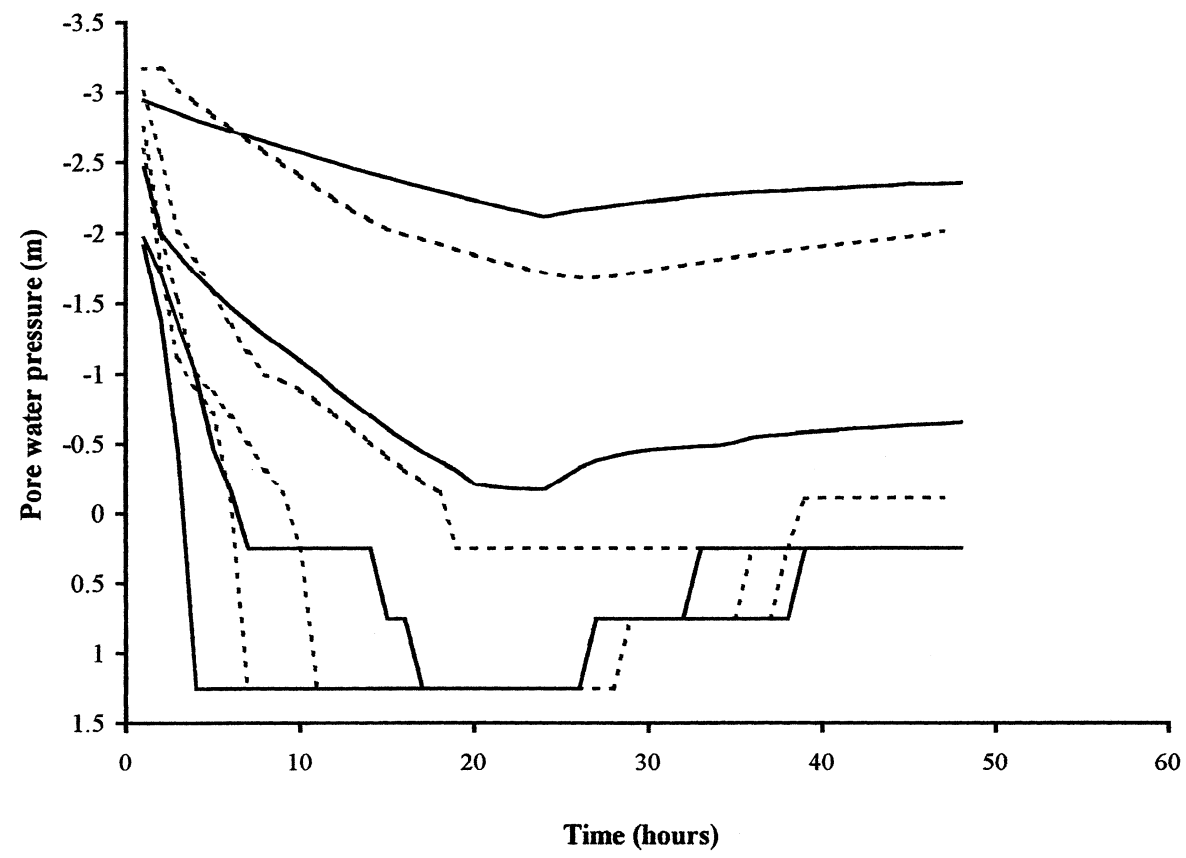

Figure 6

Detailed pore water pressure variation for different rainfall intensities $(1,10,30$ and $50 \mathrm{~mm} / \mathrm{h}$ ) and locations (solid line $=$ Hawkes Bay; dotted line $=$ Wellington).

excess water at this boundary. Even when sustained over a significant period, unsaturated conditions will persist at all depths. The pattern of pore water pressure variation involves downward migration of a wetting front such that successively greater depths respond with an increasing time lag. The deepest regions are the last to see a reduction in negative pore water pressure. The ultimate pore water pressures that could develop show a greater reduction for Wellington than for Hawke's Bay, consistent with the model results plotted in Figures $5 \mathrm{a}$ and $5 \mathrm{e}$.

The maximum probability thresholds $(12.5 \mathrm{~mm} / \mathrm{h}$ and $5.6 \mathrm{~mm} / \mathrm{h}$ for Hawke's Bay and Wellington, respectively) on the other hand, relate to rainfall intensities greater than the saturated hydraulic conductivity of each of the bedrock substrates, but still below those of each regolith type (shown as '•' on the horizontal axis in Fig. 7).

From Figure 7 it can be seen that these rates relate to similar pore water pressures in each regolith. However, at these intensities in excess of the saturated hydraulic conductivities of the bedrock, a more complex hydrological response applies. All rain enters the regolith but a point will be reached when the rate of flow through the regolith exceeds the rate of flow into the bedrock substrate. Excess water generated at the regolith-substrate boundary will further reduce the suctions in the regolith to a point where saturation is approached at this depth. It seems that with these thresholds involving rainfall intensities just in excess of the saturated hydraulic 


\section{Suction (m)}

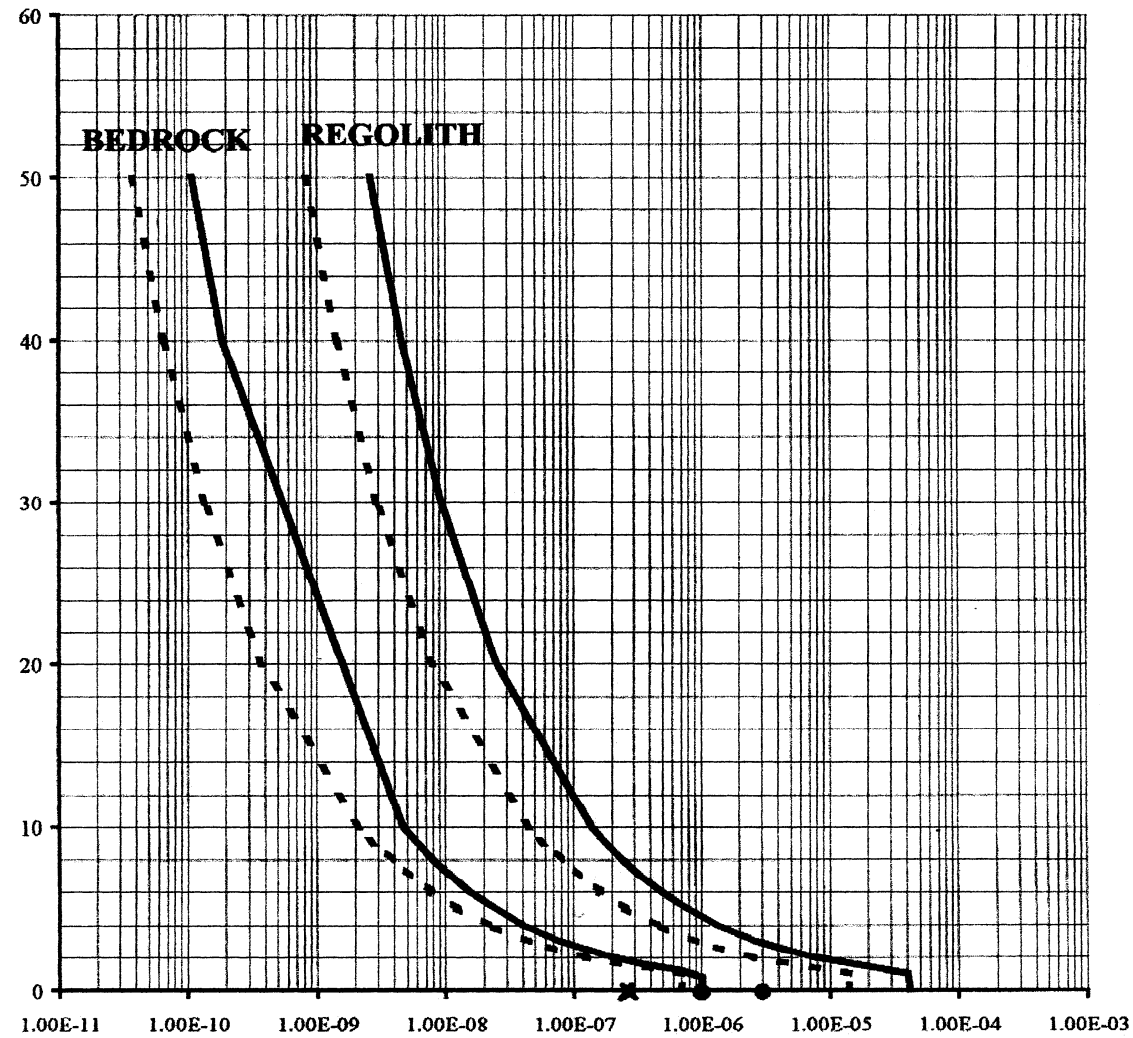

Unsaturated hydraulic conductivity $(\mathbf{m} / \mathbf{s})$

Figure 7

The relationship between unsaturated hydraulic conductivity and suction (negative pore water pressure) for regolith and bedrock substrate (solid line $=$ Hawkes Bay; dashed line $=$ Wellington) (marks along the bottom axis represent rainfall intensities corresponding the minimum and maximum probability thresholds for each location - see text).

conductivity of the bedrock but lower than those of the regolith, comparatively little excess water is generated. It is only sufficient to saturate the entire regolith if it persists for periods longer than 24 hours. According to GLADE (1997), failure will take place under these conditions. It appears that the deepest parts of the regolith will be saturated, but the high pore water pressures associated with a rise in the watertable to the ground surface are not necessarily developed. Hence the hydrological mechanisms leading to potential instability under the maximum probability threshold involve both a downward progression of a wetter zone, as well as a buildup of water at the regolith base. 
The plots relating to a rainfall intensity of $10 \mathrm{~mm} / \mathrm{h}$ (Figs. $5 \mathrm{~b}$ and $5 \mathrm{f}$ ) show these mechanisms operating. For Wellington (threshold of $5.6 \mathrm{~mm} / \mathrm{h}$ ), the shallowest depth has the fastest initial response. The deepest region experiences a rapid decline in suction only after 18 hours, once excess water begins to be generated. Hawke's Bay (threshold of $12.5 \mathrm{~mm} / \mathrm{h}$ ) requires more water for saturation given its higher porosity, and does not actually become saturated at an intensity of $10 \mathrm{~mm} / \mathrm{h}$, since this is below its threshold. The two scenarios just described, corresponding to rainfall intensities at just below the minimum probability threshold and at just above the maximum probability threshold (CASE 1 and CASE 2) are shown in Figure 8 .

At even greater rainfall intensities, two mechanisms of regolith wetting operate at each site, but with a changing balance as intensity increases. Firstly, once rainfall intensity exceeds the transmissivity of the regolith, excesses are transmitted at the ground surface. A saturated region develops and downward percolation occurs. Secondly, as the region at the regolith-substrate boundary is encountered a buildup of positive pore water pressures occurs. In these ways the entire regolith becomes saturated. The relative order in which different depths become saturated enables assessment of the changing dominance of these different hydrological mechanisms. For an intensity of $30 \mathrm{~mm} / \mathrm{h}$, significant differences are apparent in the behaviour of the Wellington and Hawke's Bay regoliths.

In the former case, this intensity is very close to the saturated hydraulic conductivity of the regolith. The surface region becomes saturated first of all (3 hours), rapidly followed by the lower regions (10 hours). All water infiltrates to bring the surface region of the regolith close to saturation. As the saturated zone migrates downwards, it encounters the deeper region where excess water is being generated, and the entire regolith becomes saturated. For Hawke's Bay, the rainfall intensity is some way below the saturated hydraulic conductivity of the regolith. In this case, regolith saturation occurs through the upward development of a perched water-table from the regolith-substrate boundary. Lower regions become saturated first of all followed by downward percolation of a wetting front. In general, it takes longer for the entire regolith to become saturated at Hawke's Bay than at Wellington, reflecting the differences in regolith hydrology.

Under a $50 \mathrm{~mm} / \mathrm{h}$ intensity, both regoliths become saturated rapidly, with Wellington again showing a response in the surface region first of all as rain enters the regolith at a rate close to the saturated hydraulic conductivity. Lower regions then become saturated due to both downward movement of the wetting front and upward movement of the perched water-table. For Hawke's Bay, all regions become saturated more-or-less simultaneously. Saturated hydraulic conductivity of the regolith remains below the rainfall intensity, hence saturation of the surface zone can take place. Both profiles ultimately become entirely saturated, but with somewhat different patterns in the way this occurs. It is also pertinent to note that several hours 


\section{CASE 1:}

$i \leq t_{\text {reg }} \leq t_{b s}$

Unsaturated conditions dominate throughout. Just below minimum probability threshold.

CASE 2:

$i \leq t_{\text {reg }}>t_{b s}$

Saturation at regolith-substrate boundary. Just above maximum probability threshold.

\section{CASE 3:}

$i>t_{\text {reg }}>t_{b s}$

Rapid attainment of total saturation (requires analysis of short duration rainfall to find thresholds).
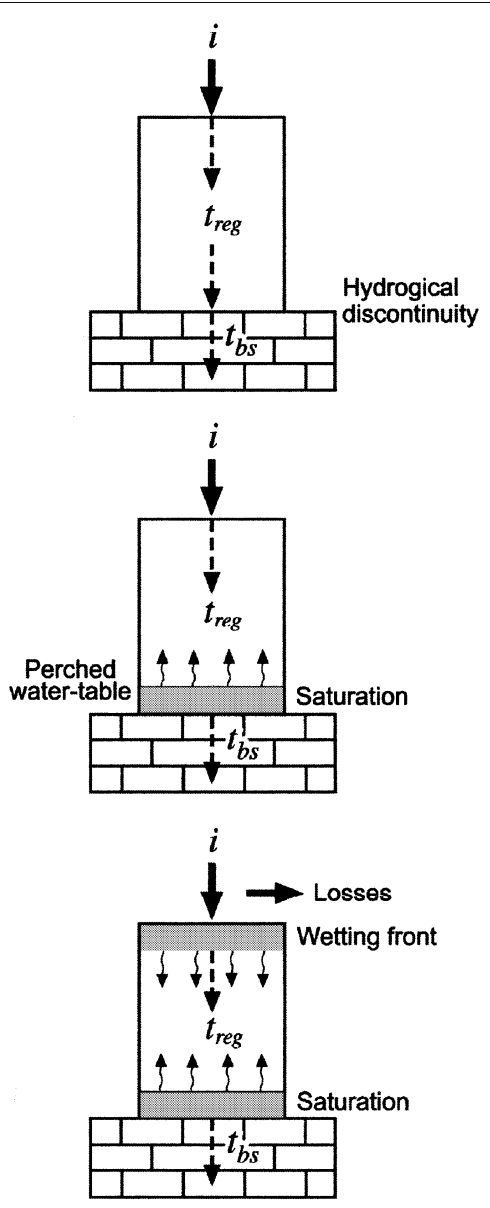

Figure 8

A revised model for assessing landslide-climate links, incorporating minimum and maximum probability theresholds.

of sustained rainfall intensities of $50 \mathrm{~mm} / \mathrm{h}$ are required for total saturation. Such conditions have unrealistically long recurrence intervals, and the implications of this will be discussed further below. The effect of high rainfall intensity in excess of the saturated hydraulic conductivity of both regolith and bedrock is shown as CASE 3 in Figure 8.

Whether slopes actually fail depends on the above hydrological responses in combination with slope angle and geotechnical properties. A slope angle of $34^{\circ}$ and an angle of internal friction of $30^{\circ}$ were used in all simulations, reflecting approximate field conditions. Figure 9 plots minimum factors of safety for the different rainfall intensities and shows that for a rainfall intensity of $10 \mathrm{~mm} / \mathrm{h}$ the 


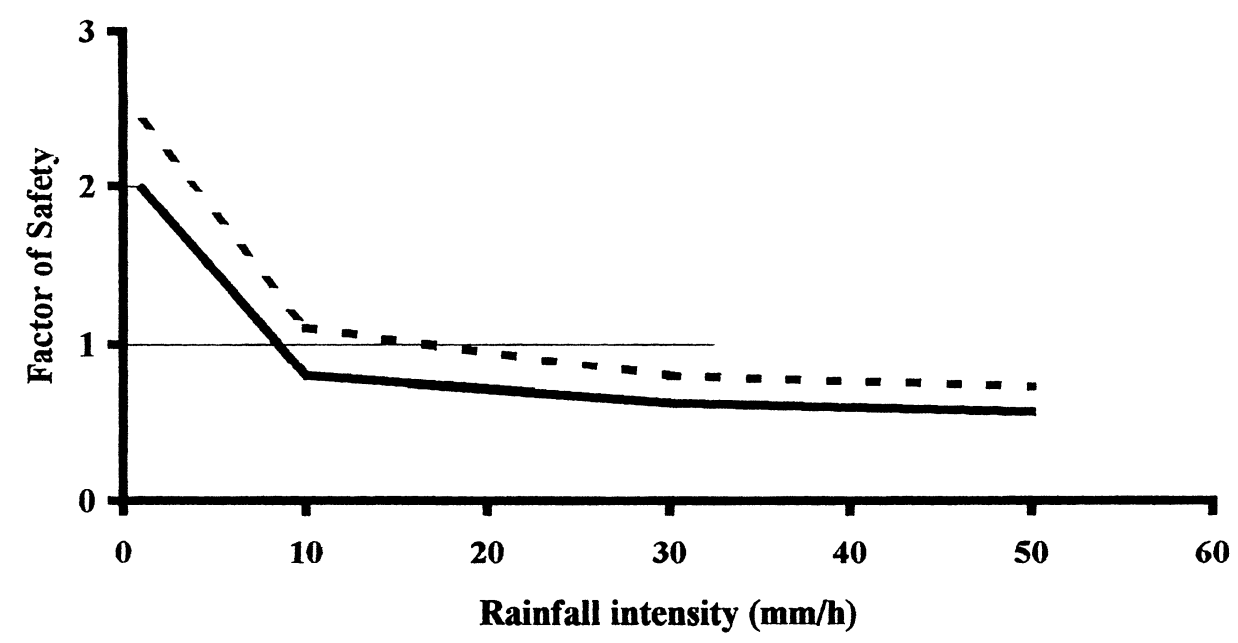

Figure 9

Factor of Safety variation with rainfall intensity showing rainfall intensity thresholds for which the factor of safety equals unity (dashed line $=$ Hawkes Bay; solid line $=$ Wellington).

Wellington slopes are unstable while the Hawke's Bay slopes are stable. This is consistent with the empirically-established maximum probability thresholds for each region, $5.6 \mathrm{~mm} / \mathrm{h}$ for Wellington and $12.5 \mathrm{~mm} / \mathrm{h}$ for Hawke's Bay. For lower rainfall intensities stability is maintained, while for higher intensities failure occurs. In both regions the point where the factor of safety reaches unity coincides closely with the field-identified daily rainfall thresholds. The fact that Hawke's Bay has a higher threshold than Wellington is established both from field observations and from model simulations, with close similarity found from both methods. The higher saturated hydraulic conductivity as well as differences in soil moisture retention curves in both the regolith and the bedrock substrate in each region account for these differences in thresholds. Further work is required to assess the significance of even greater contrasts in regolith and bedrock hydrology in combination with variations in geotechnical behaviour. Such contrasts need to be assessed in relation to antecedent moisture levels, which also have a bearing on landslide-triggering thresholds (GLADE, 1997). These are not addressed in this paper. Finally, this assessment takes no account of rainfall intensity variation within storms. These issues are the subjects of ongoing research.

\section{Discussion}

"Worst case" hydrological conditions which dictate angles of limiting stability in the landscape have been much debated since the initial suggestion that they involve 
total regolith saturation (CARson and Petley, 1970; ANDERSon et al., 1980; Brooks et al., 1993b). Originally the hydrological mechanism for total regolith saturation was thought to be rise in the groundwater system or the development of a perched water-table reaching the ground surface (CARson and PetLey, 1970). Downward migration of a wetting front was not considered. Fully-saturated conditions were thought to dominate the occurrence of shallow translational failures, and hence determine angles of limiting stability.

The hydrological response of most regolith is more complex, and involves a significant role for unsaturated zone processes as well. Hence most empirical thresholds derived from observations of landslides and rainfall characteristics are not spatially or temporally transferable. The model of CROZIER (1997) attempts to incorporate this through discussion of regolith transmissivity relative to rainfall intensity. In this model, the role of the unsaturated zone is emphasised in one of two key scenarios for interpreting the links between climate and slope failure. The basis for this model is laboratory experimentation (KIM et al., 1992). In this paper it is argued that one of the two key scenarios identified by Crozier is inapplicable in most humid temperate regions, since commonly occurring rainfall intensities almost always remain below the maximum capacity of the regolith to transmit the water.

Such conclusions were established in relation to the generation of surface runoff in humid temperate regions sometime previously, where the Hortonian infiltrationexcess mechanism for runoff generation was discounted (HORTON, 1993; SCHUMm, 1956; Chorley and Kirkby, 1969; Hewlett and Hibbert, 1967). Given the fundamental importance of subsurface hydrology to slope stability, the modified version of the CROZIER (1997) model shown in Figure 8 could form a useful framework for formulating a general scheme for the links between climate and slope failure.

The significant rainfall thresholds identified by $\operatorname{GLADE}(1997,1998,2000)$, and the model simulations carried out using $\mathrm{CHASM}^{\mathrm{TM}}$, provide a basis for interpreting the hydrological mechanisms that are fundamental to shallow translational failures. Along with a modified version of the general model of Crozier, these probability thresholds can be redefined in general terms rather than simply as a single value for the triggering rainfall intensity. A general scheme for the modified model is shown in Figure 8, emphasising the regolith-substrate boundary rather than the ground surface. The modified model makes a number of assumptions. Firstly, under most cases appropriate to humid temperate regions, regolith transmissivity at saturation is greater than rainfall intensity and all rain infiltrates. However, some high intensities may occur in excess of the regolith transmissivity, but are of comparatively short duration. Secondly, in situations where shallow regolith failure is likely to take place, bedrock transmissivity is less than regolith transmissivity at saturation. Thirdly, there is a hydrological discontinuity at the regolith-bedrock substrate boundary which is sharp and spatially continuous. 
The model suggests that for rainfall intensities below the minimum probability threshold (@1 mm/h in New Zealand), rainfall intensity is less than transmissivity of both the regolith and the bedrock substrate. The regolith and parent material remain unsaturated, hydrological response is governed by a simple downward migration of a wetting zone, and shallow translational failure is unlikely. Additional shear strength is gained through the maintenance of suctions (negative pore water pressures) in the soil. The minimum probability threshold can now be redefined as the maximum rainfall intensity that maintains unsaturated conditions within the regolith (i.e., an intensity equivalent to the maximum transmissivity of the bedrock at saturation).

The maximum probability threshold relates to the attainment of regolith saturation in the deepest regions of the profile. This occurs if rainfall intensity exceeds the saturated transmissivity of the bedrock, enabling the generation of excess water at the regolith-bedrock boundary. Continued application of rainfall at this rate will eventually lead to total regolith saturation under a mechanism involving a rise in the perched water-table to the ground surface. However, provided significant lateral throughflow does not occur, regolith transmissivity must be greater than both the rainfall intensity and the transmissivity of the substrate. This is likely in wellweathered soil profiles.

Modelling has shown that durations in excess of 24 hours are required for total regolith saturation. Partial saturation (i.e., only of the deepest region in the profile) is sufficient to promote failure. This then represents the situation for which shallow failure always occurs $(100 \%$ probability). The maximum probability threshold is redefined as the minimum rainfall intensity that allows excess water to be generated at the regolith-substrate boundary. This would lie between the saturated hydraulic conductivity of the bedrock and that of the regolith, but must be sufficient to allow the lower layers of the regolith to become saturated. In this paper a duration of 24 hours has been studied as it can readily be compared with field observations. However, higher intensities probably require shorter durations and lower intensities require higher durations for shallow failure. The intensity-duration combination that defines the maximum probability threshold requires further detailed evaluation using modelling for a range of regolith-substrate hydrological combinations, involving different amounts of lateral throughflow. However, this is more difficult to test against field conditions because rainfall totals are commonly collected over 24-hour periods.

For higher rainfall intensities equivalent to or greater than the saturated hydraulic conductivity of both the regolith and the substrate, true "worst case" conditions are generated where total regolith saturation results. This can occur due to the combination of a downward migrating saturated zone and the generation of a perched water-table at the regolith-substrate boundary. These higher intensities can create positive pore water pressures at depth in the regolith that exceed those generated at the maximium probability threshold. At the maximum probability 
threshold, partial saturation develops over a 24-hour period. The higher rainfall intensities permit more rapid attainment of "worst case" conditions, so storm durations can be lower. Again periods less than 24 hours need to be researched thoroughly.

The above discussion has focussed wholly on the hydrological controls of slope failure under varying rainfall intensities with respect to regolith-substrate hydrological behaviour. Several issues remain to be investigated further. Variations in the geotechnical behaviour of the regolith were not taken into account in the above analysis. However, once "worst case" conditions are generated, the actual slope angles which fail are those for which the combination of cohesion, friction and pore water pressure result in shear resistance dropping below the downslope shear force. The latter is determined predominantly by slope angle. It has been assumed that the two regoliths have similar geotechnical properties, and exist at similar modal slope angles to enable simple scenarios to be considered involving only variations in regolith and bedrock hydrology. The two regolith types from Wellington and Hawke's Bay are similar in that they vary only slightly in their geotechnical properties. When other regions are considered, greater variation in regolith properties is likely, and we would expect both the hydrological and the geotechnical properties to vary. This combination needs to be built into any generalised model.

Shallow regolith failures have increased in occurrence in the past 150 years largely due to vegetation removal. In this paper we have only considered slopes that have grass cover, as this is the prevailing vegetation in New Zealand hill country. It is under grassland that shallow slope failure is occurring today. However, to assess in detail how vegetation change affects slope stability we need to make intercomparisons of relative stability under different vegetation types. This is the subject of ongoing research.

Finally, we have employed simple scenarios in which the depth of regolith was kept constant in all cases. $150 \mathrm{~cm}$ represents the modal regolith depth for the slopes of both Wellington and the Tutira catchment near Hawke's Bay. The development of complete regolith saturation provides "worst case" pore pressures, with their magnitude being determined by the overlying depth of material. In the Wellington region in particular, regolith depth is relatively "variable" especially where accumulation is in hollows. Such situations require three-dimensional analysis of hydrological processes, along with the inclusion of depth effects on "worst case" pore water pressures.

The facilities offered by physically-based models are ever-increasing, extending their scope for addressing issues of significance in slope stability processes. This paper has shown how a simple application of a two-dimensional physically-based coupled soil hydrology-slope stability model has enhanced our general understanding of the links between climate and shallow regolith failure for New Zealand hill country. The model focuses on dynamic hydrology in both unsaturated and 
saturated zones, making it especially relevant to this application. Future developments linked to vegetation inclusion and representation of three-dimensional hydrology should enable further refinement of the generalised conceptual model developed in this paper, modified from the earlier work of CROZIER (1997). Hence application under a range of spatially and temporally changing conditions may be possible, to produce a transferable model of the climatic thresholds that govern shallow translational hill slope failure for a wider range of regolith-bedrock substrate combinations.

\section{REFERENCES}

Anderson, M. G., Richards, K. S., and Kneale P. E. (1980), The Role of Stability Analysis in the Interpretation of the Evolution of Threshold Slopes, Trans. Inst. Br. Geog. 5, 101-112.

Anderson, M. G., Kemp, M. J., and Lloyd, D. M. (1988), Application of soil water finite-difference models to slope stability, Proc. 5th Int. Symp. Landslides, Lausanne, 525-530.

Beven, K. J. (1989), Changing Ideas in Hydrology-The Case of Physically-based Models, Jnl. Hyd. 105, 157-172.

Beven, K. J. (1997), TOPMODEL: A Critique, Hyd. Proc 11, 1069-1085.

Brooks, S. M. Richards, K. S., and Anderson, M. G. Shallow failure mechanisms in the Holoceneutilisation of a coupled soil hydrology-slope stability model. In Landscape Sensitivity, (Thomas, D.S.G. and Allison, R.J., eds), (Wiley, Chichester, 1993a) pp. 149-174.

Brooks, S. M., Richards, K. S., and Anderson, M. G. (1993b), Approaches to the Study of Hill slope Development due to Mass Movement, Prog. Phys. Geog. 17, 32-49.

Brooks, S. M., Anderson, M. G., Ennion, T., and Wilkinson, P. L. Exploring the potential for physically-based models and contemporary slope processes to examine the causes of mass movement. In Process Modelling and Landform Evolution. (Hergarten, S. and Neugebauer, H. J., eds) Lecture Notes in Earth Sciences, (Springer, 78, 1999) pp. 205-230.

Brooks, S. M., Crozier, M. J., Preston, N., and Anderson, M. G. (2002), Regolith Evolution and the Control of Shallow Translational Hill Slope Failure: Application of a Coupled Soil Hydrology-slope Stability Model, Hawke's Bay, New Zealand, Geomorphology Au. vol. \& pg\#

CAIne, N. (1980), The Rainfall Intensity Duration Control of Shallow Landslides and Debris Flow, Geografiska Annaler 62A, 23-2.

Campbell, G. S. (1974), A Simple Method for Determining Unsaturated Conductivity from Moisture Retention Data, Soil Science 117, 311-314.

Campbell, R. H. (1975), Soil Slips, Debris Flows and Rainstorms in the Santa Monica Mountains and Vicinity, Southern California, USGS Professional Paper 851.

Carson, M. A. (1975), Threshold and Characteristic Angles of Straight Slopes, Proc. 4th Guelph Symp. on Geomorphology, 9-34.

Carson, M. A. and Petley, D. (1970), The Existence of Threshold Slopes in the Denudation of the Landscape, Trans. Inst. Br. Geog. 49, 77-95.

Chorley, R. J. and Kirkby, M. J. Introduction to Physical Hydrology (Methuen. 1969).

Crozier, M. J. Landslides: Causes, Consequences and Environment, (Routledge 1989).

Crozier, M. J. (1997), The Climate-Landslide Couple: A Southern Hemisphere Perspective, Palaeoclimate Research 2, 329-350.

Crozier, M. J. and Pillans, B. J. (1991), Geomorphic Events and Landform Response in Southeastern Taranaki, Catena 18, 471-487.

Crozier, M. J. and Preston, N. J. (1999) Modelling changes in terrain resistance as a component of landform evolution in unstable hill country. In (Hergarten, S. and Neugebauer, H. J., eds.) Lecture Notes in Earth Sciences, Springer Verlag 78, pp. 267-284. 
Crozier, M. J., Eyles, R. J., Marx, S. L., McConchie, J. A., and Owen, R. C. (1980), Distibution of Landslips in the Wairarapa Hill Country, New Zealand J. Geol. and Geophys. 23, 575-586.

Crozier, M. J., Gage, M., Pettinga, J. R., Selby, M. J., and Wasson, R. J. Stability of Hill slopes. In Landforms of New Zealand, (Soons, J. and Selby, M.J., eds) (Longman, 1992), pp. 63-90.

Crozier, M. J., Vaughan. E. E. and Tippett, J. M. (1990), Relative Instability of Colluvium-filled Bedrock Depressions, Earth Surface Processes and Landforms 15, 329-229.

DE Roo, A. P. J., Validation problems of hydrologic and soil erosion catchment models: examples from a Dutch erosion project. In Advances in Hillslope Processes (Anderson, M. G. and Brooks, S. M. eds). (Wiley Chichester, 1996) pp. 669-684.

Fawcett, K. R., Anderson, M. G., Bates, P. D., and Jordan, J-P. (1992), The Importance of Internal Validation in the Assessment of Physically-based Distributed Models, Trans. Inst. Br. Geog. NS20, 248 265.

FreEze, R. A. (1980), A Stochastic-conceptual Analysis of Rainfall-runoff Processes on a Hill Slope, Water Res. 16, 391-408.

Glade, T. W. (1997), The Temporal and Spatial Occurrence of Rainstorm-triggered Landslide Events in New Zealand, Unpublished Ph.D. Thesis, Victoria University of Wellington, Wellington, New Zealand.

Glade, T. (1998), Establishing the Frequency and Magnitude of Landslide-triggering Rainstorm Events in New Zealand, Environ. Geology 35, 160-174.

Glade, T. (2000), Modelling Landslide-triggering Rainfalls in Different Regions in New Zealand-The Soil Water Status Model, Zeitschrift für Geomorphologie 122, 63-84.

Glade, T. W. and Crozier, M. J. (1996), Towards a National Landslide Information Base for New Zealand, New Zealand Geographer 52, 29-40.

Glade, T. W., Crozier, M., and Smith, P. (2000), Applying Probability Determination to Refine Landslide-triggering Rainfall Thresholds Using an Empirical 'Antecedent Daily Rainfall Model' Pure Appl Geophys 157, 1059-1079.

Grant, P. (1983), Recently Increased Erosion and Sediment Transport rates in the upper Waipawa River Basin, Ruahine Range, Publication 5 New Zealand. Soil Conservation Centre, Aokautere.

Hennrich, K. P. (2001), Probability of Occurrence and Extent of Rainfall-induced Landslides, Hawke's Bay, New Zealand, Unpublished Ph.D. Thesis in Physical Geography, Victoria University of Wellington, $134 \mathrm{pp}$.

Hewlett, J. D. and Hibbert, A. R. (1967), Factors affecting the response of small watersheds to precipitation in humid areas. In Sopper, Forest Hydrology (W.E. and Lull, H. W. eds) (Pergamon Press, Oxford, 1967) pp. 275-290.

Horton, R. E. (1993), The Role of Infiltration in the Hydrological Cycle, Trans. Am. Geophys. Union 14, 446-460.

Jensen, E. H. (1998), The Impacts of Landslips on Contaminant Sources in Steep Pastoral Hill Country, Lake Tutira, North Island, New Zealand, Unpublished M.Sc. thesis in Physical Geography, Victoria University of Wellington, $113 \mathrm{pp}$.

KIM, S. K., Hong, W. P., and KIM, Y. M. (1992), Prediction of rainfall-triggered landslides in Korea. In Proc. 6th Int. Symp. (Bell, D.H., ed.) Christchurch, New Zealand, 989-994.

Merz, J. (1987), Hydrological Investigations of a Hillside Affected by Landslides, Lake Tutira, New Zealand, Diploma Thesis, University of Berne, Switzerland.

Millington, R. J., and Quirk, J. P. (1959), Permeability of Porous Media, Nature 183, 387-388.

Page, M. J., and Trustrum, N. A. (1997), A Late Holocene Lake Sediment Record of the Erosion Response to Land Use Change in a Steepland Catchment, New Zealand, Zeitschrift für Geomorphologie 41, 369 392.

Page, M. J., Trustrum, N. A., and DeRose, R. C. (1994), A High-resolution Record of Storm-induced Erosion from Lake Sediments, New Zealand, J. Paleolimnology 11, 333-348.

Preston, N. J. (1996), Spatial and Temporal Changes in Terrain Resistance to Shallow Translational Regolith Landsliding, Unpublished M.Sc. Thesis, Victoria University of Wellington.

Reneau, S. L., Dietrich, W. E., Rubin, M., Donahue, D. J. and Jull, A. J. T. (1989), Analysis of Hillslope Erosion Rates Using Dated Colluvial Deposits, J. Geol. 9, 45-63.

SARma, S. K (1973), Stability Analysis of Embankments and Slopes, Geotechnique 23, 423-433. 
Schumm, S. A. (1956), Evolution of Drainage Systems and Slopes in Badlands at Perth Amboy, New Jersey, Bull. Geol. Soc. Am. 67, 597-646.

Van Genuchten, M.Th. (1980), Predicting the Hydraulic Conductivity of Unsaturated soils, Proc. Soil Sci. Soc. Am. 44(5), 892-898.

Wilkinson, P. (2000), Development of a Combined Hydrology And Stability Model (CHASM $\left.{ }^{\mathrm{TM}}\right)$ to Include Vegetation Effects, Unpublished Ph.D. Thesis, University of Bristol.

(Received August 20, 2001, accepted Feburary 15, 2003)

$$
\text { (10) To access this journal online: }
$$

